\title{
A VONTADE NACIONAL NA FILOSOFIA DE CONDORCET
}

\section{THE NATIONAL WILL IN CONDORCET'S PHILOSOPHY}

Patrícia Carvalho Reis ${ }^{1}$

\section{RESUMO}

Neste artigo, analisaremos o significado da expressão "vontade nacional" no pensamento de Condorcet. Para isso, identificaremos as passagens em que o filósofo emprega esse termo e faremos uma interpretação do seu sentido. Ademais, exporemos alguns modos nos quais a vontade nacional pode aparecer nas obras desse autor. Como o iluminista esclarece, duas formas de a vontade nacional surgir são estas: quando os cidadãos interagem com os representantes na elaboração das leis ordinárias e, também, quando cidadãos e representantes participam da feitura da Constituição. Por fim, verificaremos as semelhanças e as diferenças entre as expressões "vontade nacional" em Condorcet e "vontade geral" em Rousseau.

Palavras-chave: vontade nacional, Condorcet, vontade geral;

\begin{abstract}
In this article, we will analyze the meaning of the expression "national will" in Condorcet's thought. For this, we will identify the passages in which the philosopher uses this term and we will make an interpretation of its meaning. Furthermore, we will expose the ways in which the national will can appear in the works of this author. As the philosopher clarifies, there are two ways in which the national will arises: when citizens interact with representatives in the elaboration of ordinary laws and, also, when citizens and representatives participate in the making of the Constitution. Finally, we will verify the similarities and differences between the expressions "national will" in Condorcet and "general will" in Rousseau.
\end{abstract}

Keywords: national will, Condorcet, general will;

\section{I- INTRODUÇÃO:}

Algumas expressões exercem um papel central no pensamento de determinados autores, o que não significa que elas terão uma interpretação pacífica. Basta lembrarmos que alguns leitores podem adotar uma liberdade criativa e extrapolar o alcance de certos conceitos - sejam tais

\footnotetext{
${ }^{1}$ Graduada em Direito na PUC-MG, mestre e doutora em Filosofia Política na UFMG. No mestrado, pesquisou a questão do despotismo na obra de Montesquieu. No doutorado, analisou a relação entre Constituição e soberania popular na filosofia de Condorcet. Atualmente, está investigando a relação entre Ética e Política no pensamento de Henrique Cláudio de Lima Vaz no curso de Doutorado em Direito na UFMG. Reside em Belo Horizonte. Afiliação: Universidade Federal de Minas Gerais - UFMG. Lattes: http://lattes.cnpq.br/3407088290863178. ORCID : https://orcid.org/0000-0003-3322-1507. E-mail: patricia.carvalhoreis@ hotmail.com
} 
intérpretes de uma mesma época do autor, sejam de um contexto diferente. $\mathrm{O}$ intuito deste nosso trabalho é analisar o conceito de "vontade nacional" no pensamento de Condorcet. Para isso, exporemos algumas passagens da obra condorcetiana em que tal expressão aparece. Além disso, trataremos de dois modos pelos quais a vontade nacional pode aparecer: na feitura das leis ordinárias e na feitura da Constuição. Por fim, faremos uma comparação entre a noção de "vontade geral" de Rousseau e de "vontade nacional" de Condorcet. Esse percurso nos ajudará a compreender melhor o sentido do termo, que nos parece estrutural, na filosofia do último iluminista.

\section{II- O CONCEITO DE VONTADE NACIONAL NO PENSAMENTO DE CONDORCET:}

Em suas obras, Condorcet utiliza tanto o termo "vontade nacional" quanto "vontade geral". No primeiro parágrafo da Exposition des principes et des motifs du plan de constitution ${ }^{21}$, por exemplo, Condorcet utiliza a expressão "vontade geral”: “(...) combinar as partes dessa Constituição de maneira que a necessidade de obediência às leis, de submissão das vontades individuais à vontade geral, deixe subsistir em toda a sua extensão a soberania do povo (...) (CONDORCET, 2013, p. 63). Por sua vez, o termo "vontade nacional" é empregado em alguns exemplos que daremos a seguir. Consideramos que Condorcet utiliza esses diferentes termos com o mesmo sentido. Entretanto, salientamos que, quando formos tratar dessas expressões no pensamento de Condorcet e de outros autores, seremos fiéis ao adotar a terminologia utilizada por eles.

Como salienta Newton Bignotto, o termo "vontade geral" era usado desde o século XVII por pensadores como Arnauld, Pascal, Malebranche e outros. Segundo esse intérprete, para Malebranche, tratava-se de algo natural e, por isso, podia se tornar geral sem que os homens tivessem de interferir (BIGNOTTO, 2010, 164).

No século XVIII, esse termo se tornou célebre na obra de Rousseau. Alguns anos mais tarde, como salienta Lucien Jaume, a ideia de vontade geral está no coração da ideologia revolucionária e é sem cessar invocada no discurso dos diversos grupos que sustentam o processo engajado (dos monarquistas à extrema esquerda) (JAUME, 1989, 221).

No texto Instrução sobre o exercício do direito de soberania, Condorcet nos esclarece o que entende por vontade nacional:

\footnotetext{
211A partir de agora, designaremos essa obra como Plano de Constituição, assim como os tradutores para o português deste texto, Amaro Fleck e Cristina Foroni. Ela precede a Declaração de Direitos e o Projeto de Constituição. A maioria dos intérpretes considera que Condorcet atuou quase que exclusivamente na elaboração desses Plano de Constituição e Projeto de Constituição. Salientamos, ainda, que, regra geral, utilizaremos as obras de Condorcet publicadas por A. Condorcet O’Connor e M.F. Arago, de 1847. Utilizaremos, também, o livro com textos político-constitucionais de Condorcet traduzidos para português mencionado nesta nota-de-rodapé.
} 
Quando a universalidade de uma nação votou nas assembleias, convocadas segundo uma forma estabelecida pela lei (...), o desejo da maioria dos cidadãos presentes nessas assembleias, ou daquela maioria dessas assembleias, é a expressão da vontade nacional (...) (CONDORCET, 1847d, 536-537).

No texto Das convenções nacionais, de 1791, Condorcet afirma que, no momento em que os homens sentiram a necessidade de viver de acordo com regras comuns, eles viram que tais regras não poderiam ser a expressão de uma vontade unânime (CONDORCET, 1847b, 193). Portanto, numa sociedade livre, cada indivíduo deve ter opinião própria. Como afirma Charles Coutel, a unanimidade existe para respeitar a opinião da parte majoritária e executar a lei após o voto (COUTEL, 1996, 133).

No escrito Da natureza dos poderes políticos em uma nação livre, Condorcet retoma essa ideia ao afirmar que a submissão à vontade da maioria é fundada sobre a necessidade de haver uma regra comum de ação e sobre o interesse de preferir a regra comum, que será mais frequentemente conforme à razão e ao interesse de todos (CONDORCET, 1847a, 590). Em decorrência disso, mesmo aquele que não concordar com a regra da maioria, deve obedecer a ela; caso contrário, outros poderiam ter uma postura parecida, e, dessa maneira, não seria possível estabelecer regras comuns. Assim, segundo o iluminista, os indivíduos devem-se abstrair de sua opinião no momento em que obedecem às leis.

Também salientamos que, para Condorcet, a vontade nacional não deve violar direitos de minorias. Assim, os cidadãos serão convocados a manifestar suas opiniões apenas sobre questões que não violem os direitos individuais expressos na Declaração dos Direitos dos Cidadãos. (CONDORCET, 1847f, 415). Na seguinte passagem, Condorcet manifesta, de modo claro, esse seu pensamento: “(...) o poder da maioria sobre a minoria não deve ser arbitrário, ele se estende até onde não violar o direito de um indivíduo" (CONDORCET, 1847a, 590). Percebemos, assim, que, para Condorcet, a ideia de democracia e a de proteção de direitos devem ser complementares. Em outras palavras, segundo Condorcet, o voto majoritário não deve se sobrepor à proteção dos direitos dos cidadãos.

Além disso, segundo Condorcet, para constatar a vontade nacional, todos os cidadãos do país devem manifestar-se após uma atuação prévia dos representantes. Portanto, a vontade nacional somente pode ser averiguada após ocorrer o diálogo entre representantes e cidadãos. Assim, a título de exemplo, a vontade nacional pode ser constatada quando os cidadãos ratificam o texto constitucional elaborado pelos representantes ou quando os cidadãos afirmam que a proposição, feita por um cidadão ou pelos representantes, de mudança do texto constitucional merece ser levada 
em consideração. Em outras palavras, a averiguação da vontade nacional depende de um mecanismo geral de interações entre representantes e cidadãos. Como afirma Pierre Rosanvallon:

A vontade geral apresenta para ele [Condorcet] uma característica duplamente complexa. Longe de ser um dado preexistente à atividade política, resulta de um processo contínuo de interação e reflexão entre o povo e os representantes. As estruturas ordinárias do governo representativo e os procedimentos de referendo ou de censura do povo são complementares: eles constituem dois momentos e duas formas, ao mesmo tempo, de soberania de povo. Essa abordagem é extraordinariamente inovadora (ROSANVALLON, 2000, 61).

Percebemos, portanto, que Condorcet se opõe à ideia de que a vontade nacional pode ser obtida constatando apenas a vontade dos representantes ou apenas a dos cidadãos. Por outro lado, alguns consideram que a vontade nacional pode ser alcançada apenas pela averiguação da vontade dos representantes. Na perspectiva de um rei absoluto, sua vontade representa a vontade da nação. De modo não muito divergente, para alguns, a voz de uma assembleia legislativa é a voz dos cidadãos. Seguindo esse pensamento, para Emmanuel Joseph Sieyès, a vontade geral está relacionada com a manifestação das vozes dos representantes. Nesse sentido, o art. 26 de sua Declaração dos Direitos dispõe: “A lei pode ser apenas a expressão da vontade geral. Num grande povo, ela deve ser a obra de um corpo de representantes escolhidos por um curto tempo, direta ou indiretamente por todos os cidadãos que se ligam à coisa pública por seus interesses e capacidades" (SIEYÈS, 1994, 205, grifo nosso).

$\mathrm{Na}$ época do governo revolucionário, alguns deputados do Comitê de Salvação Pública também passaram a associar a vontade nacional com a deles próprios. Tais deputados passaram a defender a ideia de que os legisladores tinham a tarefa de "criar o povo". Nessa situação, portanto, eles determinariam aquilo em que os cidadãos deveriam acreditar. Assim, a vontade da nação deveria ter íntima relação com uma ideologia. Nesse sentido, a vontade nacional se identificaria com a vontade de uma assembleia de representantes "virtuosos", a qual, ao defender a criação de um povo, além de desprezar as vontades individuais, seria a favor de eliminar os que se comportassem de modo contrário ao modelo do "homem virtuoso".

Diante dessas concepções de vontade nacional, percebemos que todas elas, com exceção da de Condorcet, tratam o povo como um ente abstrato. O último iluminista, por sua vez, associa o povo à soma de cidadãos pertencentes a um país: em decorrência disso, a vontade nacional deve ser constatada por meio da contagem dos votos de cada cidadão.

É importante salientar, ainda, que, na época da Revolução, alguns indivíduos que não ocupavam cargos institucionais também passam a identificar suas vontades com aquela do povo. Assim, percebemos que eles também adotam o discurso de falar em nome do povo, dando a entender que sabem qual seria a vontade nacional. Como afirma Gabriele Magrin, inicia-se, em agosto de 
1792, uma nova fase política da Revolução caracterizada por uma relação instável entre o povo e a representação nacional. Assim, nesse período, o movimento popular, com seus centros propulsores nas seções, nos clubes e, sobretudo, na Comuna Insurreicional de Paris, passa a interferir nas decisões políticas da Convenção. Diante disso, uma "minoria ativa" começa a progressivamente falar em nome do povo soberano (MAGRIN, 2007, 133-135).

Em resposta a esse discurso, na obra Instrução sobre o exercício do direito de soberania, Condorcet afirma que nenhuma parte das seções do povo deve ter o direito de recolher, constatar ou declarar a vontade nacional (CONDORCET, 1847d, 537-538).

Ora, como já mencionamos, Condorcet se opõe a que algumas pessoas afirmem qual seja a vontade da nação sem consultá-la. Como os representantes ou alguns cidadãos podem saber quais são as vozes dos membros da nação se há divergência de opiniões entre os próprios representantes e os próprios cidadãos? Segundo Condorcet, a presença dos representantes é de fundamental importância para que os cidadãos possam demonstrar suas vozes, de modo institucionalizado, sobre diversos assuntos relacionados à política, inclusive sobre as leis. Isso, por sua vez, é bastante diferente de os representantes poderem, sozinhos, dizer qual seja a voz da nação. Do mesmo modo, como mencionamos, alguns cidadãos não podem afirmar qual seja a vontade do povo: para que a vontade nacional possa ser obtida, cada cidadão deve ter oportunidade de demonstrar sua opinião.

\section{III- FORMAS DE SE CHEGAR À VONTADE NACIONAL NO PENSAMENTO DE CONDORCET:}

Segundo Condorcet, os cidadãos podem manifestar suas vozes sobre as leis ordinárias e também sobre a Constituição. No Plano de Constituição assim como no Projeto de Constituição, Condorcet trata dos modos pelos quais os cidadãos podem interferir na feitura das leis. Não temos o objetivo de analisar de forma detalhada os trâmites processuais dessa tarefa. Entretanto, consideramos importante salientar as ideias centrais do iluminista sobre os modos pelos quais tanto cidadãos quanto representantes pronunciarão suas vozes em relação à feitura dessas leis.

De acordo com Condorcet, para que o cidadão proponha mudança numa lei ordinária, ele deve solicitar ao escritório de sua assembleia primária ${ }^{32}$ a convocação dela para o domingo mais próximo a fim de deliberar sobre sua proposição. É necessário, ainda, que 50 indivíduos residentes no distrito da mesma assembleia primária afirmem que essa proposta de mudança da

\footnotetext{
${ }^{3} 22$ Segundo Condorcet, o território francês deveria ser dividido em 85 departamentos; estes seriam divididos em comunas que, por sua vez, seriam divididas em seções municipais e em assembleias primárias. Cada cidadão seria integrante de uma assembleia primária, e cada uma delas não teria menos de 450 membros nem mais de 900 . Condorcet salienta, ainda, que, em cada assembleia, ocorreria a nomeação de um escritório composto de um membro para cada 50 cidadãos (CONDORCET, 2013, 130-132).
} 
lei mereça ser submetida à assembleia primária - eles não precisam concordar que essa proposição seja justa, apenas devem manifestar se esse assunto merece ser levado em consideração (CONDORCET, 2013, 130-132).

Cumprido esse requisito, o escritório da assembleia primária tem o direito de convocar, para examinar a proposição que ela própria admitiu, todas as assembleias de uma circunscrição mais extensa do território. Se a resolução da maioria dos membros destas assembleias for no sentido de que o requerimento de mudança legal mereça ser analisado, as assembleias de uma circunscrição ainda mais extensa serão convocadas. Por conseguinte, se a resolução da maioria destas assembleias primárias também considerar que tal assunto deve ser levado em consideração, a assembleia dos representantes do país deverá manifestar se deve ocupar-se dessa questão. Caso a assembleia de representantes considere que ela não se deve ocupar dessa questão, a universalidade das assembleias primárias da República será convocada para responder a mesma pergunta: tal assunto deve ser levado em consideração? Nessa hipótese, duas situações são possíveis: ou a maioria das assembleias primárias se declara a favor da opinião dos representantes e, assim, a proposição é rejeitada; ou essa maioria exprime uma resolução contrária. Nesse caso, a assembleia de representantes deve ser renovada, uma vez que ela parece ter perdido a confiança nacional (CONDORCET, 2013, 76),

Desse modo, Condorcet cria oportunidades para que cada cidadão possa manifestar sua voz em relação às leis. Nessa situação de propositura de lei por um cidadão, o movimento se inicia na sociedade, pode alcançar os membros do poder legislativo, pode retornar à sociedade e, por fim, pode fazer com que ocorra a destituição dos representantes. Nesse caso, os cidadãos da república, e não os representantes, têm a última palavra sobre o requerimento de um cidadão concernente à propositura ou à reforma da lei.

Essa convocação dos cidadãos às assembleias primárias para pronunciar se consideram pertinente a propositura de mudança na lei faz com que eles sejam incitados a demonstrar suas vozes na atividade legislativa. De acordo com Condorcet, se os cidadãos não forem convocados a demonstrar suas opiniões, somente a voz daqueles que têm um comportamento mais ativo na política aparecerá:

(...) (eles) têm necessidade que uma Constituição lhes mostre, de uma maneira certa, qual é seu interesse e seu dever, a fim de que possam aprender sem dificuldade em direção a que objetivo devem reunir seus esforços; e, uma vez que sua massa imponente tenha sido conduzida em direção a esse objetivo comum, a porção ativa dos cidadãos cessa de parecer o povo inteiro (...) (CONDORCET, 2013, 122).

Para Condorcet, a existência de procedimentos previstos na lei para que os cidadãos demonstrem suas vontades faz com que mesmo os indivíduos desinteressados pela política 
manifestem suas opiniões. Portanto, Condorcet tenta criar meios artificiais que possibilitem os cidadãos demonstrarem suas vozes sobre as leis. Ao fazerem isso, exercerão seu direito de soberania.

No caso de feitura da Constituição, Condorcet defende que ela seja feita por uma assembleia constituinte, também chamada de convenção nacional, e pelos cidadãos (CONDORCET, 2013, 168). Ao defender a existência de convenções nacionais periódicas para revisar a Constituição de um país, Condorcet pretende que os cidadãos sejam incitados a se pronunciar sobre ela. Isso, por sua vez, fará com que eles interajam com seus representantes. Segundo Condorcet, uma Constituição que estimule a participação dos cidadãos na feitura das leis traz estabilidade a uma sociedade. Essa ideia é clara na seguinte passagem:

\begin{abstract}
O modo de evitar insurreições é então dominar a vontade do povo pela razão, forçálo, esclarecendo-o, não a se curvar diante da lei, mas a querer se submeter a ela. $\mathrm{O}$ modo de evitar insurreições é então organizar reclamações regulares, igualmente irresistíveis, que forçam a soberania nacional a pronunciar sua voz. O modo de prevenir revoluções é dar aos cidadãos a facilidade de as fazerem sob uma forma legal e pacífica (CONDORCET, 1847 a, 612).
\end{abstract}

Percebemos, assim, que, no caso da elaboração da Constituição, Condorcet não se contenta com a existência de canais abertos de diálogo entre cidadãos e representantes. Para o iluminista, periodicamente, os membros de uma assembleia constituinte devem revisar a Constituição, e os cidadãos devem manifestar se concordam ou não com o novo plano constitucional apresentado por essa assembleia. Nesse sentido, concordamos com a afirmativa de Urbinati de que Condorcet tenta criar procedimentos capazes de fazer da inovação legal uma fonte de estabilidade e melhoramento (URBINATI, 2006, 182). Portanto, a atuação dos cidadãos na feitura de sua Constituição não deve ser dependente da demanda de mudança constitucional por algum cidadão ou representante. De tempos em tempos, a revisão constitucional deve ocorrer. Podemos afirmar que a instauração de convenções nacionais periódicas fará com que o espírito público dos cidadãos se mantenha sempre ativo. Utilizando o termo de Paine, consideramos que tais convenções darão estâmina - capacidade vital para a manutenção de uma atividade - para que os cidadãos atuem na feitura das leis. Em outras palavras, consideramos que Condorcet tem o objetivo de deixar acesa uma chama do espírito revolucionário nos cidadãos. Entretanto, essa chama deve ser controlada pelas instituições. Assim, Condorcet tenta achar uma forma pela qual cidadãos e membros das instituições democráticas demonstrem suas vozes periodicamente. 
Pierre-François-Joseph Robert ${ }^{43}$, deputado da Convenção Nacional, faz críticas a esse pensamento de Condorcet. Segundo ele, caso os cidadãos fossem convocados constantemente a participar da elaboração das leis, somente aqueles com recurso, de fato, iriam fazê-lo. No dia 26 de abril de 1793, ele afirma diante dos demais deputados:

\begin{abstract}
Se vós decretásseis essas frequentes assembleias, a parte menos favorecida do povo estaria na impossibilidade absoluta de participar delas, e, se ela não participa dessas assembleias, seu direito ao exercício da soberania seria apenas ilusório: a classe favorecida, opulenta, tornar-se-ia a senhora suprema das assembleias, e, por um excesso de democracia mal-entendida, vós veríeis, necessariamente, se elevar um gênero de aristocracia bem terrível, a aristocracia quase absoluta dos ricos (ARCHIVES PARLAMENTAIRES, LXIII, 386).
\end{abstract}

Observamos que Robert tem receio de que um regime incentivador de medidas democráticas acabe se tornando menos democrático pelo fato de a classe menos favorecida não ter tempo para participar dos assuntos referentes aos interesses da coletividade. Assim, segundo esse pensador, o democratismo extremo se inverte no seu contrário. E qual seria o papel que os cidadãos deveriam exercer na atividade legislativa na visão dele? Em sua obra $O$ republicanismo adaptado à França, de 1790, Robert afirma:

As menores como as maiores comunidades são reunidas para nomear seus oficiais municipais, seus administradores, seus juízes; elas se reunirão para nomear novos representantes: não poderíamos reuni-las igualmente a certas épocas para consentir ou rejeitar as decisões da assembleia nacional? (ROBERT, 1790, 99).

Desse trecho, percebemos que Robert é a favor de que os cidadãos participem da atividade legislativa. Entretanto, ele imagina formas que não demandem dos cidadãos uma atuação tão frequente nessa atividade como as propostas por Condorcet.

Robespierre também critica o modelo proposto por Condorcet de participação dos cidadãos na feitura das leis. Segundo ele, a participação excessiva dos indivíduos nos assuntos públicos prejudicaria o sustento de suas famílias. Para compensar essas tarefas, o Estado teria que dar uma indenização aos cidadãos (MONTFORT, 1915, 205).

Marat também se opõe à atuação dos cidadãos nas assembleias primárias defendida por Condorcet. Para o "Amigo do Povo", não há sentido em convocar os cidadãos nas assembleias primárias para opinar sobre a proposta de uma nova lei ou a reforma de uma já existente.

\footnotetext{
433Robert e sua esposa exerceram um grande papel no ramo jornalístico, sendo responsáveis pela criação do Jornal do Estado e do Cidadão (SOBOUL, 1989, 912). Robert foi também redator do Mercure National e um dos principais porta-vozes das sociedades patrióticas na primavera de $1791 \mathrm{e}$, desde 1790, se declarava republicano (antes da fuga do rei à Varennes) (BIGNOTTO, 2010, 236). Percebemos, assim, que Robert se declarava republicano numa época em que poucos se manifestavam contra a monarquia.
} 
Segundo ele, isso pode ser perfeitamente feito por um deputado. No artigo Sobre a nova constituição, de 18 de fevereiro de 1793, essas suas ideias estão claras:

\begin{abstract}
Nesse plano [de Constituição de Condorcet], os corpos administrativos e os tribunais têm funções bastante extensas, mas são as assembleias primárias que exercem o grande papel, pois elas estão sem cessar em movimento pela menor coisa, de sorte que os autores do plano de Constituição não dão outra ocupação aos cidadãos senão a de reunir e a de deliberar (...) Quem acreditaria que, para propor uma nova lei ou mudar uma antiga, isso que se pode fazer tão simplesmente por um simples deputado, fosse preciso manter cinco milhões de homens de prontidão por seis semanas? É um ato de loucura (...) (MARAT, 1869, 275).
\end{abstract}

Condorcet admite que, nos países em que três quartos da população são submetidos aos trabalhos cotidianos, os cidadãos não podem ter a incumbência de elaborar, sozinhos, sua legislação. Como acrescenta o iluminista, isso determinaria a destruição absoluta da igualdade e até mesmo da liberdade (CONDORCET, 1847e, 539). Diante disso, Condorcet pensa em meios pelos quais os cidadãos possam participar da feitura das leis de modo constante sem que isso prejudique seus afazeres pessoais. A atividade legislativa dos cidadãos poderia ocupar uma pequena parte de seus dias. Além disso, Condorcet defende a existência de alguns requisitos para que os cidadãos sejam convocados a pronunciar suas vozes nas assembleias primárias. Se, por exemplo, a maioria dos cidadãos de uma comuna não considerar que determinada proposição mereça ser analisada, os cidadãos pertencentes às assembleias primárias de um departamento não serão convocados a se manifestar.

Ao defender essas questões, observamos que Condorcet defende a existência de uma espécie de "legislador coletivo", conceito do qual os cidadãos fazem parte. Desse modo, Condorcet combate a figura da autoridade representada por poucos legisladores dotados de uma capacidade extraordinária de impor as leis. Ora, para Condorcet, os legisladores são pessoas comuns que devem atuar junto aos cidadãos na atividade legislativa. Como estamos tentando demonstrar neste trabalho, para Condorcet, a Constituição deve servir como instrumento incitador da atuação dos cidadãos na feitura das leis.

Ao interpretar as ideias de Condorcet sobre a atuação dos cidadãos na feitura das leis, Coutel afirma que "o cidadão condorcetiano é plenamente um ator e jamais um espectador nos assuntos públicos"(COUTEL, 1999, 100). Coutel emprega o seguinte termo para definir a doutrina que Condorcet parece seguir: "méliorisme politique". Tal doutrina, por oposição ao otimismo e ao pessimismo, é aquela segundo a qual o mundo pode se tornar melhor pelos esforços do homem adequadamente dirigidos (COUTEL, 1996, 250).

Assim como Coutel, reconhecemos que o pensamento de Condorcet em relação à atuação dos cidadãos e dos representantes na atividade legislativa depende de um esforço. Em 
outras palavras, uma sociedade democrática não surge de modo espontâneo. Ora, o iluminista não parece duvidar que, num país populoso, seria mais simples os cidadãos delegarem de forma integral seus direitos políticos aos representantes. Entretanto, para Condorcet, isso implicaria também a delegação de sua liberdade. Em decorrência disso, o esforço que os cidadãos teriam que efetuar para participar da feitura das suas leis é compensador.

Tendo em vista essas ideias, resta-nos responder a seguinte questão: será que a dificuldade da concretização das ideias de Condorcet sobre a atuação dos cidadãos na feitura das leis não representa o preço que se deve pagar para viver num regime democrático? Consideramos preferível existir mecanismos à primeira vista complexos, mas que permitam aos cidadãos demonstrar a quais regras eles gostariam de se submeter, a deixar alguns poucos indivíduos interferirem nesse assunto. Essa ideia de que o regime democrático exige um esforço para se concretizar nos lembra o pensamento de Montesquieu em relação à dificuldade de se instaurar um regime moderado:

Para formar um governo moderado, é mister combinar os poderes, regulamentá-los, moderá-los e fazê-los agir; oferecer, por assim dizer, um lastro a um para colocá-lo em condição de resistir a outro; é uma obra-prima de legislação que o acaso raramente produz e que também raramente deixa-se à prudência fazer (MONTESQUIEU, 1979, 74).

Num primeiro momento, poderíamos pensar que o regime democrático é ainda mais difícil de ser realizado do que o regime moderado. Entretanto, não estamos certos se esse tipo de comparação é pertinente. Na realidade, para Condorcet, a concretização do regime democrático depende da atuação dos cidadãos, e não somente da dos representantes, na atividade legislativa. Desse modo, diríamos que, para Condorcet, o regime democrático, diferentemente do regime moderado, necessita que os cidadãos junto a seus representantes se esforcem no intuito de manter esse regime. Portanto, de nosso ponto de vista, o regime democrático não é mais difícil de ser realizado que o regime moderado, mas depende sim da atuação de toda a sociedade para a sua realização e não apenas da dos representantes.

Segundo Condorcet, a atuação dos cidadãos na feitura das leis é possível de ocorrer e, além disso, traz resultados compensadores, uma vez que os cidadãos se imporão as leis e, como consequência, deixarão de ser submissos a seus representantes. Apresentadas essas ideias, trataremos, a seguir, das reflexões de Condorcet sobre a elaboração da Constituição pelos representantes e pelos cidadãos. Como veremos, além das regras mencionadas acima, a feitura da Constituição exige algumas específicas.

Um ponto que merece ser enfatizado é que, para Condorcet, a interação entre os cidadãos e os representantes deve ser passível de ocorrer a qualquer momento. Em outras palavras, Condorcet 
não entende que a vontade nacional seja algo que se constata numa determinada ocasião específica, uma vez que essa interação pode ocorrer quando os membros das assembleias primárias de todo o país são convocados a demonstrar suas vozes sobre o requerimento de mudança legal proposto por um cidadão e também quando os cidadãos se manifestam, periodicamente, sobre a Constituição elaborada pelos representantes. Em decorrência disso, na concepção de Condorcet, a vontade nacional não tem um conteúdo engessado. Nesse sentido, concordamos com a afirmativa de Jaume de que, no modelo de soberania de Condorcet, a vontade geral se torna um processo e não uma entidade (JAUME, 1989, 318). Seguindo esse raciocínio, Rosanvallon afirma que a vontade geral para Condorcet é uma construção histórica (ROSANVALLON, 2000, 61) ${ }^{54}$.

Percebemos, portanto, que a vontade nacional em Condorcet não é simplesmente a vontade da maioria dos cidadãos. Identificar esses termos sem dar maiores explicações poderia levar a uma interpretação errada do conceito de vontade nacional no pensamento do iluminista. Na realidade, para Condorcet, a vontade nacional é a vontade da maioria obtida da interação, de modo institucionalizado, entre cidadãos e representantes - passível de ocorrer a qualquer momento -, e que, além disso, não contrarie os direitos dos cidadãos.

Segundo Condorcet, após se chegar à vontade nacional, cabe aos representantes declará-la: “(...) os representantes têm o direito, não de formar, ou mesmo interpretar a vontade nacional, mas declará-la, após tê-la recolhida e constatada" (CONDORCET, 1847d, 538). O iluminista ainda diz que, se a vontade nacional não é evidente, se ela não é formalmente pronunciada, cabe aos representantes advertirem o povo de que é preciso que sua vontade seja conhecida para que seja executada (CONDORCET, 1847d, 538).

É ainda importante salientar que o art. $3^{\circ}$ do Projeto de Declaração dos Direitos de fevereiro de 1793 tem o seguinte conteúdo: “A conservação da liberdade depende da submissão à lei, que é a expressão da vontade geral" (CONDORCET, 2013, 125). Não sabemos se Condorcet foi o redator desse artigo. Entretanto, diante das considerações apresentadas acima, uma interpretação literal dessa frase poderia ser incongruente com as ideias de Condorcet sobre os autores das leis. Ora, a rigor, Condorcet defende que somente as leis constitucionais devem, necessariamente, ser expressão da vontade nacional. Condorcet considera que, no futuro, todas as leis sejam ratificadas pelos cidadãos para terem validade. Porém, no momento em que escreve, Condorcet defende que as leis ordinárias podem ser elaboradas exclusivamente pelos membros do poder legislativo. Portanto, elas podem ser válidas sem um prévio diálogo entre representantes e cidadãos. Nesse caso, tais leis não

\footnotetext{
${ }^{5} 44 \mathrm{Tal}$ concepção de vontade nacional lhe rendeu algumas críticas. Saint-Just, por exemplo, apesar de não apresentar uma definição para o conceito de vontade geral, fez o seguinte comentário: "Pareceu-me que o comitê (de Constituição) tinha considerado a vontade geral sob seu aspecto intelectual; a vontade geral puramente especulativa, resultando mais das vias de espírito que do interesse do corpo social, as leis sendo a expressão do gosto mais do que da vontade geral", em: (ARCHIVES Parlamentaires de 1787 a 1860, Tome LXIII, 1903, 203).
} 
são expressão da vontade nacional, mas sim expressão da vontade dos representantes eleitos pelos cidadãos. Entretanto, como mencionado, Condorcet admite a hipótese de as leis poderem vir a ser a expressão da vontade nacional quando um cidadão propõe uma mudança nessa lei, e os demais cidadãos assim como os representantes estabelecem um diálogo sobre essa propositura.

Após essas considerações, teremos condições de fazer uma breve comparação entre o conceito de vontade nacional em Condorcet e o conceito de vontade geral em Rousseau no item a seguir. Salientamos, já neste momento, que não temos a pretensão de fazer uma análise profunda do conceito de vontade geral no pensamento do filósofo genebrino, uma vez que isso fugiria do propósito deste nosso artigo. O que pretendemos expor é a possível influência de Rousseau na elaboração do conceito de vontade nacional de Condorcet.

\section{IV- A VONTADE NACIONAL EM CONDORCET E A VONTADE GERAL EM ROUSSEAU:}

Como o filósofo genebrino afirma, a vontade geral se relaciona com o interesse comum que pode ser reconhecido por todos (ROUSSEAU, 1987, 44). Segundo Lourival Gomes Machado, é preciso ressaltar que o interesse comum não diz respeito a uma confluência de interesses particulares, mas ao interesse de todos e de cada um enquanto componente do corpo coletivo e exclusivamente nesta qualidade. Em outras palavras, a vontade geral seria o que há de comum em todas as vontades particulares ${ }^{65}$.

Seguindo as lições de Bignotto, para Rousseau, uma sociedade democrática republicana somente pode se constituir a partir da expressão inicial da vontade geral e com a identificação do bem comum como polo central de construção da cidadania (BIGNOTTO, 2010, 170). Bignotto ainda afirma que, segundo Rousseau, a manifestação da vontade geral é o momento zero do corpo político e que, nesse momento, não é possível existir representação. Seguindo esse intérprete, a representação depende do outro, de alguém exterior, e isso deve ser evitado por constituir uma ameaça (BIGNOTTO, 2010, 167) ${ }^{76}$.

Ao associar a vontade nacional com a vontade da maioria proveniente do diálogo entre representantes e cidadãos, Condorcet parece enfatizar as vozes dos cidadãos num corpo político já constituído. Assim, Condorcet não faz a mesma abordagem de Rousseau mencionada acima. Isso, por sua vez, não significa que Rousseau não trate da vontade geral num corpo político já constituído.

\footnotetext{
655Ideia presente na nota de rodapé da obra Do Contrato Social (ROUSSEAU, 1987, 44).

${ }^{7} 66$ Apesar de defender essa ideia, Rousseau defende a existência, no momento de instituição do corpo político, do que ele denomina de legislador. Como afirma o filósofo genebrino, o legislador é o indivíduo que ousa empreender a instituição de um povo (ROUSSEAU, 1987, 57).
} 
Quando afirma que as leis são atos da vontade geral, Rousseau quer dizer que as leis não devem ser expressão de uma vontade particular (ROUSSEAU, 1987, 55). Consideramos que essa afirmativa pode ser aplicada a um corpo político já constituído. Segundo Rousseau, para que uma vontade seja geral, nem sempre é necessário que seja unânime, mas é preciso que todos os votos sejam contados. Qualquer exclusão formal rompe a generalidade (ROUSSEAU, 1987, 45). Ao interpretar essa passagem de Rousseau, observamos que, para ele, a vontade geral pode ser a vontade da maioria, desde que tal regra seja consagrada de forma unânime numa primeira convenção. Isso significa que a regra da maioria também é uma convenção. Como tenta elucidar Rousseau, caso não haja convenção anterior, a menos que a eleição fosse unânime, onde estaria a obrigação de se submeterem os menos numerosos à escolha dos mais numerosos? Donde sai o direito de cem que querem um senhor, votar em nome de dez, que não o querem de modo algum? Portanto, a lei da pluralidade dos sufrágios é, ela própria, a instituição de uma convenção e supõe, ao menos por uma vez, a unanimidade (ROUSSEAU, 1987, 31).

Nesse sentido, percebemos que, para Rousseau, num corpo político já constituído, a vontade geral pode ser a vontade relacionada com o interesse comum de uma maioria. Por sua vez, no momento de fundação de um corpo político, a vontade geral deve ser relacionada com o interesse comum, que diz respeito à unanimidade das vozes. Assim, podemos concluir que, segundo o filósofo genebrino, a lei pode ser expressão da vontade da maioria desde que esta tenha sido obtida num corpo político já constituído.

Nesse aspecto, Condorcet e Rousseau parecem falar a mesma língua. É importante também salientar que essa vontade da maioria, para Rousseau, também nasce do diálogo entre representantes e cidadãos. Apesar de Rousseau afirmar que a vontade não se pode transmitir e que o soberano, sendo um ser coletivo, somente pode ser representado por ele mesmo ${ }^{87}$, consideramos que Rousseau não é contra a participação do representante na feitura das leis junto aos cidadãos num corpo político já constituído.

Como afirma Rousseau, é nula toda lei que o povo diretamente não ratificar; em absoluto, não é lei (ROUSSEAU, 1987, 108). Cabe ao povo, por sua vez, somente ratificar as leis. Como salienta expressamente Rousseau, os membros do Governo devem ter a incumbência de opinar, propor, dividir e discutir as leis (ROUSSEAU, 1987, 118). Assim, em nosso ponto de vista, a vontade geral em Rousseau, num corpo político já constituído, apresenta muitas semelhanças com a vontade nacional em Condorcet, uma vez que, para o filósofo genebrino, tal vontade também é a vontade da maioria nascida de um diálogo entre cidadãos e representantes.

\footnotetext{
${ }^{8} 77$ Essa ideia está no Capítulo I do Livro II do Contrato Social.
} 
Como mencionamos, Rousseau considera que toda lei deve ser expressão da vontade geral. Condorcet, por sua vez, como salientamos, se contenta, a princípio, em defender que apenas as leis constitucionais sejam expressão da vontade nacional. Para esse filósofo, as leis ordinárias podem ser resultado da vontade nacional.

\section{V-CONCLUSÃO:}

Diante dessas considerações, percebemos que, para Condorcet, a ideia de vontade nacional consiste na vontade da maioria, desde que não viole direitos das pessoas, surgida após a interação entre cidadãos e representantes. Como ressaltamos, também, a Constituição deve ser expressão da vontade nacional e as leis ordinárias podem ser expressão dessa vontade. Para Condorcet, essas não são as únicas formas de expressão da vontade nacional. Entretanto, elas mereceram um lugar de destaque no pensamento de nosso autor.

A título de conclusão, percebemos que tais ideias de Condorcet refletem um pensamento republicano de que as pessoas devem se engajar na política e de que não devem deixar que apenas alguns ditem ordens que terão reflexos em suas vidas. Em suma: Condorcet nos alerta de que a vontade do povo não é, certamente, o que muitos dizem que é. A vontade do povo é uma construção, por isso, é o resultado de um processo e, para que seja legítimo, todo cidadão deve ter o direito de manifestação de sua voz, por vias institucionais e nos moldes mencionados acima, garantido. Temos consciência de que uma participação tão ativa dos cidadãos na política parece algo distante da realidade na qual muitos de nós lutam para sobreviver. De qualquer modo, consideramos bastante pertinentes as considerações de Condorcet sobre a democracia representativa.

Por fim, salientamos que ficaremos satisfeitos se, mais do que apresentar o pensamento de um filósofo pouco estudado no nosso meio, conseguirmos transformar a leitura deste trabalho num convite para refletirmos o conceito apresentado acima, neste nosso momento político presente. Certamente, ficaremos incomodados quando alguém, mesmo que seja o governante do nosso país, nos diga qual é a vontade nacional sem antes nos questionar por meios institucionais e de forma constante e pacífica.

\section{VI- REFERÊNCIAS BIBLIOGRÁFICAS:}

ARCHIVES parlamentaires de 1787 a 1860. Recuéil complet des débats législatifs et politiques des Chambres françaises. Tome LXIII, Paul,Dupont Editeur. Paris, 1903.

BIGNOTTO, Newton. As aventuras da virtude: as ideias republicanas na França do século XVIII. São Paulo: Companhia das Letras, 2010. 
CONDORCET. Escritos políticos-constitucionais. Organização, tradução e apresentação: Amaro de Oliveira Fleck e Cristina Foroni. Prefácio: Newton Bignotto. Campinas: Editora Unicamp, 2013.

CONDORCET. De la nature des pouvoirs politiques dans une nation libre. In : CONDORCET O’CONNOR; F. ARAGO (orgs.). Oeuvres de Condorcet. Paris : Firmin Didot Frères, 1847a, Tome $\mathrm{X}$.

CONDORCET, Des Conventions Nacionales, in : A. CONDORCET O'CONNOR E F. ARAGO (orgs.), Oeuvres de Condorcet, Paris, Firmin Didot Frères, 1847b, Tome X, 193.

CONDORCET. Exposition des principes et des motifs du plan de constitution. In: A. CONDORCET O'CONNOR E F. ARAGO (orgs.). Oeuvres de Condorcet. Paris: Firmin Didot Frères, $1847 \mathrm{c}$, Tome XII.

CONDORCET. Instruction sur l'exercice du droit de souveraineté. In: CONDORCET O'CONNOR; F. ARAGO (orgs.). Oeuvres de Condorcet. Paris : Firmin Didot Frères, 1847d, Tome $\mathrm{X}$.

CONDORCET. Réponse à l'adresse aux provinces, ou Réflexions sur les escrits publiés contre l'assemblée nationale. In: A. CONDORCET O'CONNOR E F. ARAGO (orgs.). Oeuvres de Condorcet. Paris: Firmin Didot Frères, 1847e. Tome IX.

CONDORCET, Sur la nécessité de faire ratifier la constitution par les citoyens et sur la formation des communautés de campagne, in: A. CONDORCET O'CONNOR E F. ARAGO (orgs.), Oeuvres de Condorcet, Paris, Firmin Didot Frères, 1847f, Tome IX.

COUTEL, CHARLES, Condorcet: instituer le citoyen. Paris: Éditions Michalon, 1999.

COUTEL, CHARLES, Politique de Condorcet, Paris, Éditions Payos \& Rivages, 1996.

JAUME, Lucien. Le discours jacobin et la démocratie. Paris: Librairie Arthéme Fayard, 1989.

MAGRIN, Gabriele. Condorcet: um constituzionalismo democratico. Milão: Francoangeli, 2007.

MARAT, J. P. Oeuvres de J P Marat recueillies et annotées par A. Vemorel. Paris: LibraireÉditeur, 1869.

MONTESQUIEU. Do Espírito das Leis. São Paulo: Abril Cultural, 1979.

MONTFORT, H. Archambault de. Les idées de Condorcet sur le suffrage.Paris: Societé française d'Imprimerie et de Librairie, 1915.

ROBERT, François. Le republicanisme adapté à la France. 1790.

ROSANVALLON, Pierre. La démocratie inachevée. Histoire de la souveraineté du peuple en France. Paris: Éditions Gallimard, 2000.

ROUSSEAU. Do Contrato Social. São Paulo: Nova Cultural, 1987.

SIEYÈS, E.J., Preliminaire de la Constitution, in: ROBERTO ZAPPERI (org.), Emmanuel-Joseph Sieyès. Écrits politiques, Paris, Éditions des archives contemporaines, 1994. 
SOBOUL, Albert. Dictionnaire historique de la révolution française. Paris: Presses Universitaires de France, 1989.

URBINATI, Nadia. Representative Democracy Principles \& Genealogy. Chicago: The University of Chicago Press, 2006.

Trabalho recebido em 02 de outubro de 2021

Aceito em 31 de outubro de 2021 